\title{
Excitation control of a power plant alternator using interval type-2 fuzzy logic controller
}

\author{
Manoj Kumar Sharma ${ }^{1}$, R.P. Pathak ${ }^{2}$, Manoj Kumar Jha ${ }^{3}$, M.F. Qureshi ${ }^{4 *}$ \\ ${ }^{1}$ NIT Raipur, Chattisgarh, India \\ ${ }^{2}$ Mathematics, NIT Raipur, Chattisgarh, India \\ ${ }^{3}$ Naveen K.T.C. College Salni, Janjgir-Champa, Chattisgarh, India \\ ${ }^{4}$ Department of electrical Engg, DTE, Raipur, Chattisgarh, India
}

Corresponding Author Email: mfq_pro@rediffmail.com

https://doi.org/10.18280/ama_c.730407

Received: 17 May 2018

Accepted: 25 September 2018

\section{Keywords:}

synchronous machine, excitation control, dynamic stability, interval type 2 fuzzy logic controller, FLC

\begin{abstract}
This paper presents a practical design of an intelligent type of controller using Interval Type2 Fuzzy Logic Controller (IT2FLC) concepts for excitation control of a practical power generating system. This type of controller is suitable for real time operation and aims to improve the dynamic characteristics of the generating unit by acting properly on its original excitation system. The modeling of the power system under study consists of a synchronous generator connected via a transformer and a transmission line to an infinite bus. Next, digital simulations of the above system are performed using fuzzy control techniques that are based on previous work. The dynamic performances of the interval type-2 fuzzy logic controllers (IT2FLC) along with Interval type-1 Fuzzy logic controller in short FLC is presented by comparison using the integral square error criterion (ISE). Typical transient responses of the system are shown for comparison in order to demonstrate the effectiveness of the proposed controller. The computer simulation results obtained demonstrate clearly that the performance of the developed controller offers competitive damping effects on the generator oscillations, with respect to the associated ones of the FLC, over a wider range of operating conditions, while their hardware implementation is easier and the computational time needed for real-time applications is drastically reduced. In MATLAB/SIMULINK is simulated model of the synchronous generator connected to an AC system. A simple fuzzy logic control scheme is simulated for voltage control and generator stabilization.
\end{abstract}

\section{INTRODUCTION}

The effect of the high-speed excitation on dynamic stability is to add negative damping to the system thereby causing oscillations with weak damping. A design of such an excitation system should also be satisfactory for a wide range of operating conditions as well as for fault conditions. Practical methods for nonlinear control include an open-loop inverse model of the nonlinear plant dynamics and the use of feedback loops to cancel the plant nonlinearities. The approximation of a non-linear system with a linearized model yields to the application of adaptive control, where real-time measurements of the plant inputs are used, either to derive explicitly the plant model or design a controller based on this model (indirect adaptive control), or to directly modify the controller output (direct adaptive control) [1-6]. Typical studies concerning applications of modern algebraic and optimal control methods in excitation controller design using linear system models and output feedback have been presented before. Fuzzy approaches to intelligent control schemes treat situations where some of the dining relationships can be described by fuzzy sets and fuzzy relational equations [7-12]. Fuzzy logic controllers (FLCs) constitute knowledge- based systems that include fuzzy rules and fuzzy membership functions to incorporate human knowledge into their knowledge base. Some studies concerning applications in excitation controller design using fuzzy set theory have been developed before. Most knowledge-based systems rely upon algorithms that are cumbersome to implement and require extensive computational time. Fuzzy logic provides an inference that enables approximate human reasoning capabilities to be applied to knowledge-based systems. The results are compared with those of the FLC [13-18]. The overall evaluation of the proposed controller is made through the ISE criterion. The computer simulation results obtained over a number of simulations clearly illustrate that there are potential capabilities of this proposed approach. It is also demonstrated that the performance of the developed controller will offer competitive damping effects on the generator oscillations over a wider range of operating conditions, with the associated ones of the FLC design. Electrical power system generally consists of some generating unit, transmission line, and load center. The fault is always occurred in the electrical power system, whether it is a permanent one or temporary one. The fault in electrical power system can caused deviation on system's variables, such as voltage, frequency and others. This deviation can affect the stability of system. Stability in electrical power system is defined as an ability of electrical power system to maintain synchronization during and after fault occurred. Nowadays IT2FLC based PSS has possibility to be designed and implemented with a new controller based on a modern and sophisticated technology such as artificial intelligent. In artificial intelligent methods, fuzzy logic is really interesting, because it does not need mathematical approach to give control solution [19-23]. Fuzzy logic and fuzzy sets are fundamental element for fuzzy systems, where 
their objective is to model brain manipulates inexact information. So this method is suitable for a complex system and non-linear. Fuzzy set is introduced first time by Zadeh in 1965 to manipulate data and information which unprobabilistic and uncertain. Further development on type-1 fuzzy set is interval type-2 fuzzy set. Interval type-2 fuzzy set is used to model uncertainty and imprecision in a better way. Interval type-2 fuzzy set is introduced at the first time at 1975 by Zadeh and developed by Mendel with characterizing interval type-2 fuzzy set as Footprint of Uncertainty (FOU) [24-28]. FOU is limited by superior and inferior type-1 membership function. The development of fuzzy set from type- 1 to interval type- 2 in most cases always shows a better result.

\section{EXCITATION SYSTEM}

Excitation current is provided by the excitation system usually consists of autonomic voltage regulator (AVR), exciter, measuring elements, IT2FLC based power system stabilizing Controller and limitation and protection unit (Fig.1). Exciter is the source of electrical power for the field winding of generator and is realized as a separate DC or AC generator. Exciter has its field winding in the stator, and armature winding in the rotor. In case of $\mathrm{AC}$ generator, as the rotor rotates, stator DC current induces a three-phase alternating current into the rotor winding. This AC current is rectified using diode, thyristor or transistor bridge installed in the rotor. Exciter is controlled by the AVR, which is very effective during steady-state operation, but, in case of sudden disturbances it may have negative influence on the damping of power swings, because then it forces field current changes in the generator.

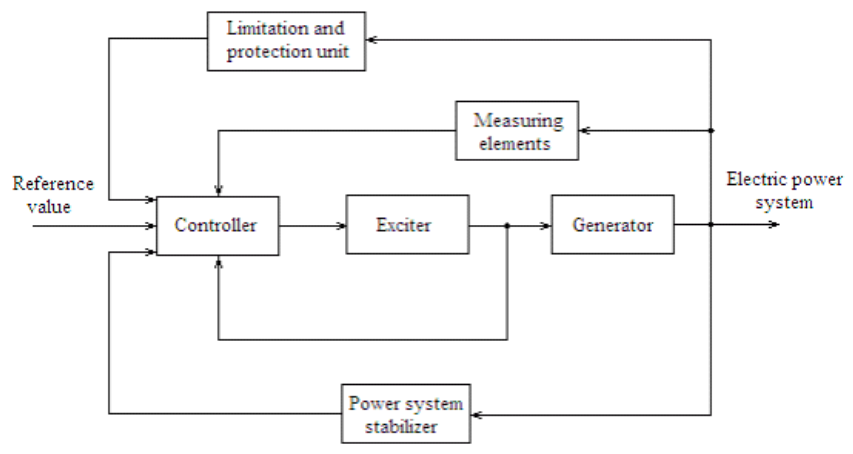

Figure 1. Excitation system of synchronous generator

This may be eliminated by introducing a supplementary control loop, the IT2FLC based power system stabilizing Controller, which produces an additional signal into control loop and in that way compensates voltage oscillations. The typical range of oscillation frequencies is of 0.1 to $3.0 \mathrm{~Hz}$ and insufficient damping of these oscillations may limit the ability to transmit power. IT2FLC based PSS input quantities may be speed deviation, generator active power, frequency deviation, transient electromotive force and generator current. Usually two of these input quantities are chosen to get optimal regulation. Measuring elements are used to obtain excitation system input values. Generator armature voltage is always measured and measurements of armature current and the excitation current and voltage are optional. Limitation and protection unit contains larger number of circuits which ensure that certain physical values (e.g. generator armature voltage, excitation current, etc.) are limited.

\subsection{Alternator model under study}

The power system model to which the new proposed controller design is applied consists of an $87.5 \mathrm{kVA}$ alternatorset model connected via a transformer and transmission line to an infinite bus, is shown here in Fig. 2. The machine model was selected to have parameters broadly typical of those associated with larger machines. This approach can facilitate hardware changes as required and allows for practical tests to be carried out without disruptions in main generator sources. The main parameters for this machine for practical purposes are shown in the Appendix A. It is readily seen that the perunit reactances are representative of turbogenerators in the range of 20-30 MW.

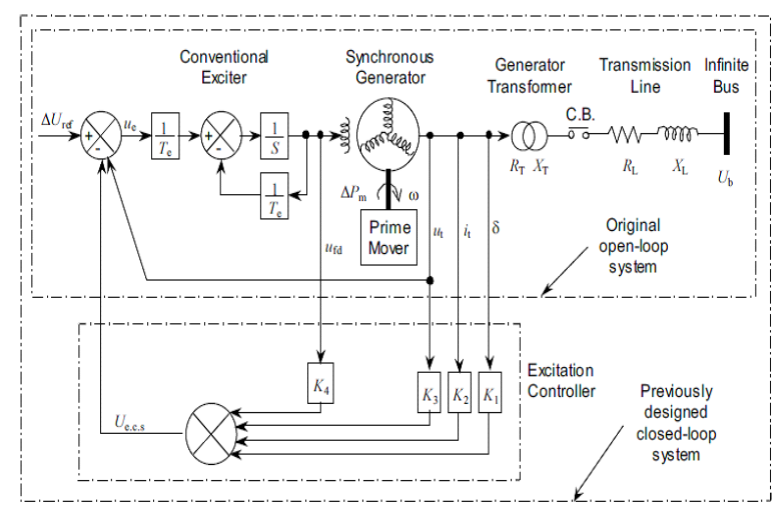

Figure 2. Simplified representation of synchronous machine plus exciter supplying power to the electric utility system through an interconnection network

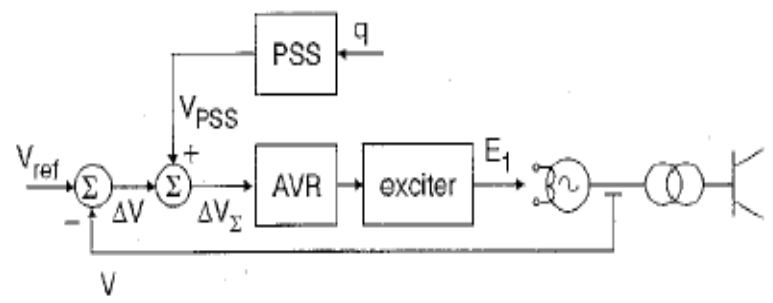

Figure 3. Functional diagram of excitation control

Obtained resulting to an $8^{\text {th }}$ order transformed closed- loop model as well as to its associated reduced $4^{\text {th }}$ order model. Finally, the $8^{\text {th }}$ order transformed open-loop model was combined with the designed controller of the latter $4^{\text {th }}$ order closed-loop model to give an $8^{\text {th }}$ order transformed closed-loop model that resulted in improved overall performance.

\section{CONFIGURATION OF THE FUZZY LOGIC CONTROLLER}

Structure of the fuzzy logic excitation control is presented on the fig. 4. The fuzzy controller has two control loops. The first one is the voltage control loop with the function of automatic voltage control and the second one is the damping control loop with the function of power system stabilizer. A simple fuzzy polar control scheme is applied to these two control loops. The detailed configuration of the fuzzy logic 
controller is presented on the fig. 5 . The voltage error signal is the difference between the voltage reference $\mathrm{Vr}$ and the actual voltage $\mathrm{Vt}$. The PD information of the voltage error signal e is utilized to get the voltage state and to determine the reference for the PI control loop. The PI control loop is used to control the generator voltage without error. Output of the fuzzy logic stabilizing controller is the reference for the excitation current regulator. The damping control signal $\mathrm{Ud}$ is derived from the PD information of the generator speed. $\mathrm{Za}$ is a measure of the acceleration of generator and $\mathrm{Zs}$ is a measure of the speed deviation. $\mathrm{Za}$ and $\mathrm{Zs}$ are derived from active power of the generator through filters and an integrator. The damping control signal Ud is added to the input of the voltage control loop.

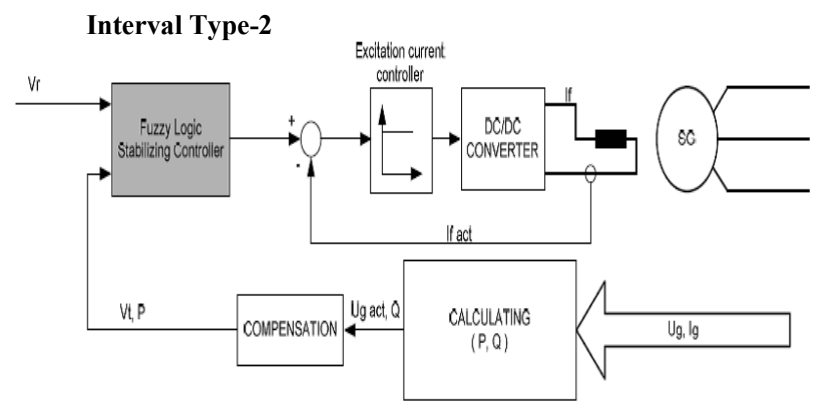

Figure 4. Structure of the fuzzy logic excitation control

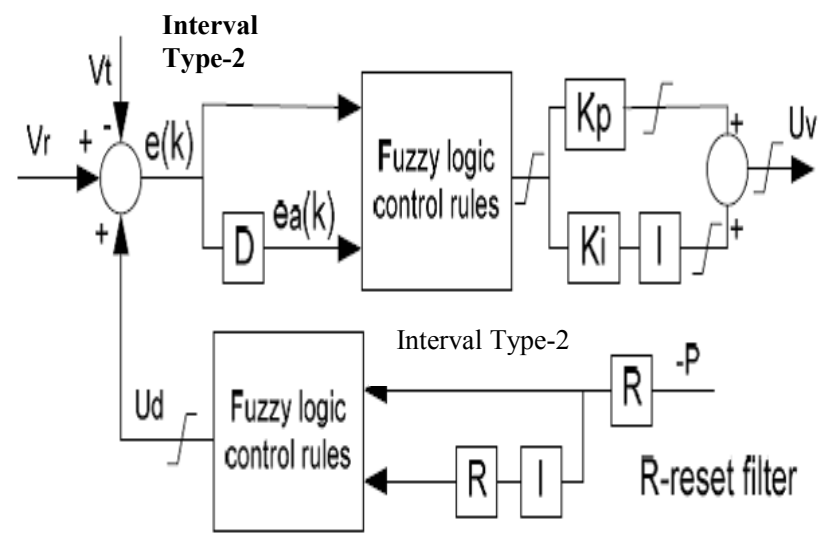

Figure 5. Configuration of the fuzzy logic excitation controller

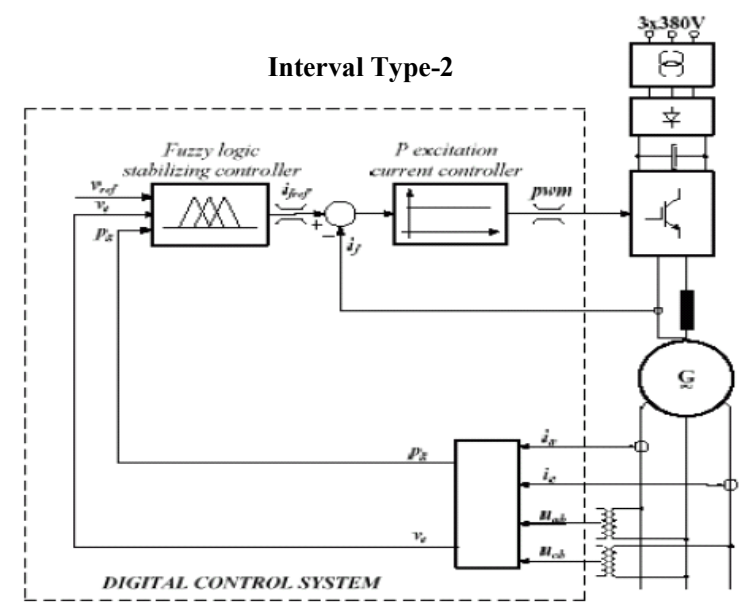

Figure 6. Block diagram of fuzzy logic excitation control
The fuzzy controller has two control loops: voltage control loop and damping control loop, and in that way unifies AVR and PSS. Fuzzy controller shows improved static as well as dynamic operating conditions. Fig. 6 shows block diagram of fuzzy logic excitation control.

\section{THE PROPOSED INTERVAL TYPE-2 FUZZY LOGIC CONTROLLER}

An Interval Type-2 Fuzzy Logic Controller is similar with Type-1 Fuzzy Logic Controller, but instead using type-1 Fuzzy Logic as a controller IT2FLC uses Interval Type-2 Fuzzy Logic as the controller. The explanation about Interval Type-2 Fuzzy Logic and its application, IT2FLPSS, are explained as follows:

\subsection{Interval type-2 fuzzy logic}

Membership function in interval type-2 fuzzy logic set as an area called Footprint of Uncertainty (FOU) which limited by two type-1 membership function those are: Upper membership Function (UMF) and Lower Membership function (LMF) [6, 7]. Interval type-2 membership function is shown in Fig. 7.

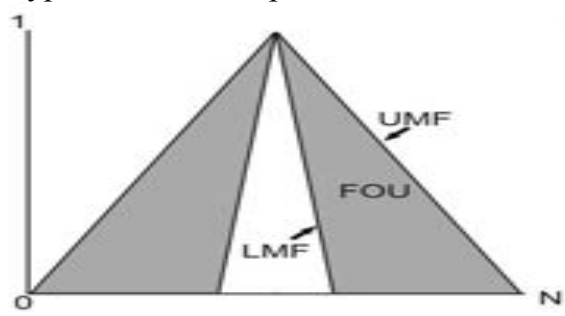

Figure 7. Membership function interval type-2 fuzzy logic set

Operation at Interval type-2 fuzzy set is identical with an operation on type-1 fuzzy set, however on interval type-2 fuzzy system; fuzzy operator is done at two type-1 membership function which limits the FOU, UMF and LMF to produce firing strength. Operation on interval type-2 fuzzy logic is shown in Figure 8.

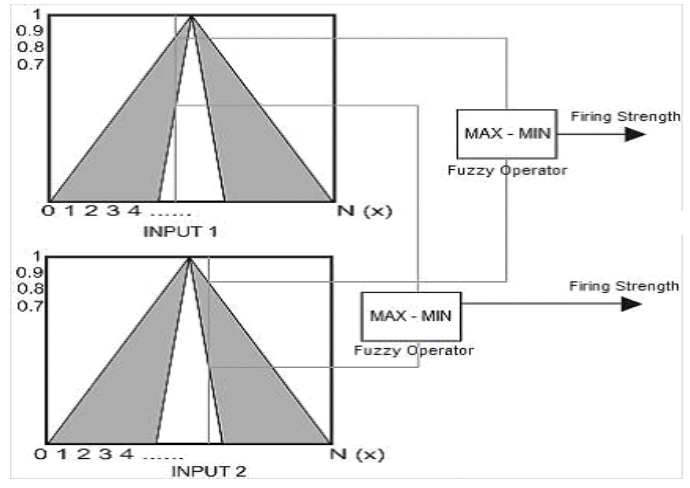

Figure 8. Operation on interval type-2 membership function

Fuzzy Inference System (FIS) which used in this paper is Mamdani method, or used to call Max-Min method. On Mamdani FIS it needs 5 steps to produce an output: Fuzzyfication, Membership function operation, Implication function, Aggregation, and Defuzzyfication. A simple example of Mamdani Fuzzy Inference System on "dinner for 
two" on interval type-2 fuzzy logic system is shown in Fig. 9. Defuzzyfication is a mapping process from fuzzy logic control action area to a non-fuzzy (crisp) control action area. Defuzzyfication on an interval type-2 fuzzy logic system that use centroid method has been proposed by Karnik and Mendel, known as Karnik-Mendel Algorithm. The Karnik-Mendel Algorithm flow chart is shown at Fig.10.

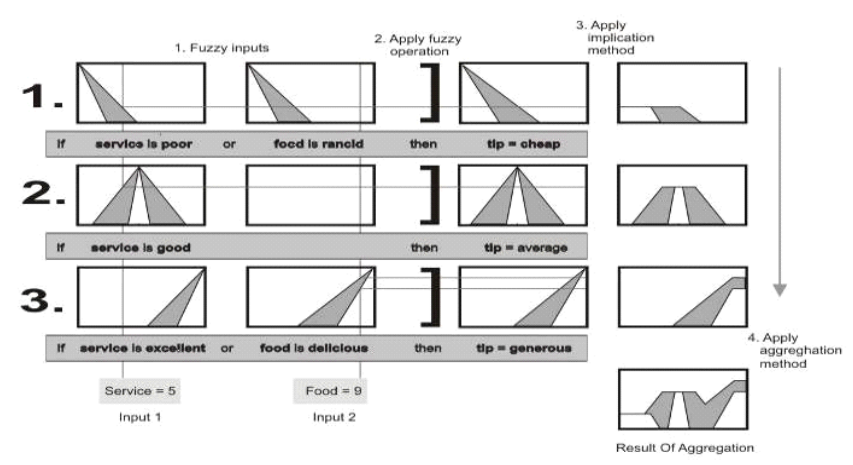

Figure 9. Mamdani fuzzy inference system centroid on interval type-2 fuzzy logic

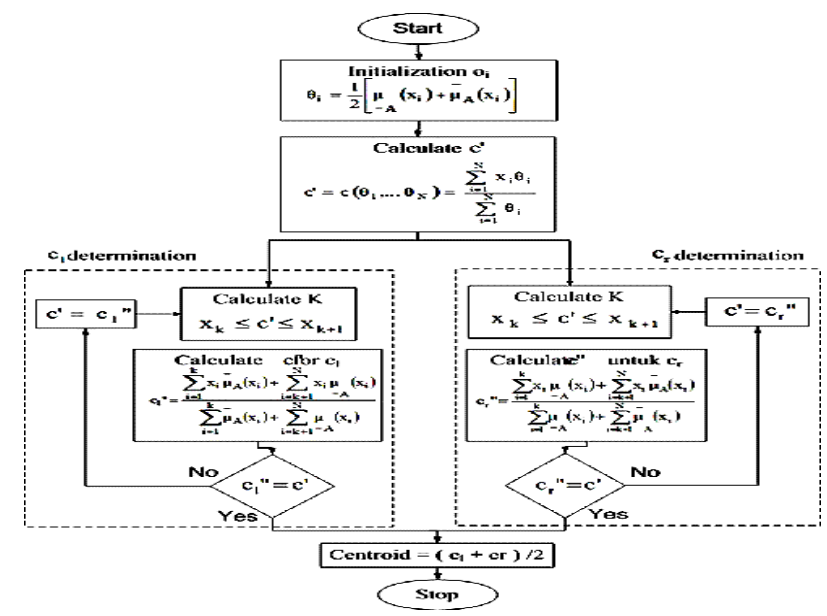

Figure 10. Karnik-mendel algorithms to locate on interval type-2 fuzzy logic

The Karnik-Mendel Algorithm flow chart at Fig.10 can be explained as follows:

\subsection{The ci determination}

1) Initialization of $\theta_{i}$, through equation (1)

$\theta_{\mathrm{i}}=\frac{1}{2}\left[\underline{\underline{\mu}}\left(\mathrm{x}_{\mathrm{i}}\right)+\bar{\mu}\left(\mathrm{x}_{\mathrm{i}}\right)\right] \quad \mathrm{i}=1, \ldots, \mathrm{N}$

2) Calculate $c^{\prime}$ through equation (2)

$c^{\prime}=c\left(\theta_{i}, \ldots, \theta_{N}\right)=\frac{\sum_{i=1}^{N} x_{i} \theta_{i}}{\sum_{i=1}^{N} \theta_{i}}$

3) Calculate $K$ value, so it fulfills equation (3)

$\mathrm{x}_{\mathrm{k}} \leq \mathrm{c}^{\prime} \leq \mathrm{x}_{\mathrm{k}+1}$
4) Calculate $c$ " through equation (4)

$\mathrm{c}^{\prime \prime}=\frac{\sum_{\mathrm{i}=1}^{\mathrm{k}} \mathrm{x}_{\mathrm{i}} \bar{\mu}_{\mathrm{A}}\left(\mathrm{x}_{\mathrm{i}}\right)+\sum_{\mathrm{i}=\mathrm{k}+1}^{\mathrm{N}} \mathrm{x}_{\mathrm{i}} \underline{\mu}_{\mathrm{A}}\left(\mathrm{x}_{\mathrm{i}}\right)}{\sum_{\mathrm{i}=1}^{\mathrm{k}} \bar{\mu}_{\mathrm{A}}\left(\mathrm{x}_{\mathrm{i}}\right)+\sum_{\mathrm{i}=\mathrm{k}+1}^{\mathrm{N}} \underline{\mu}_{\mathrm{A}}\left(\mathrm{x}_{\mathrm{i}}\right)}$

5) Check, if $\mathrm{c}{ }_{1}=\mathrm{c}^{\prime}$ than stop. If not, set $\mathrm{c}^{\prime}=\mathrm{c}{ }_{1}$ then return to step number 2 .

\subsection{The cr determination}

1) Initialization $\theta_{i}$, through equation (1)

2) Calculate $c^{\prime}$ through equation (2)

3) Calculate $\mathrm{k}$ value, so it fulfills equation (3)

4) Calculate c" through equation (5)

$$
c^{\prime \prime}=\frac{\sum_{i=1}^{k} x_{i} \underline{\mu}_{A}\left(x_{i}\right)+\sum_{i=k+1}^{N} x_{i} \bar{\mu}_{A}\left(x_{i}\right)}{\sum_{i=1}^{k} \underline{\mu}_{A}\left(x_{i}\right)+\sum_{i=k+1}^{N} \bar{\mu}_{A}\left(x_{i}\right)}
$$

5) Check, if $\mathrm{c}{ }_{\mathrm{r}}=\mathrm{c}^{\prime}$ than stop. If not, set $\mathrm{c}^{\prime}=\mathrm{c}{ }_{\mathrm{r}}$ then return to step number 2 .

\subsection{Centroid calculation}

The $\mathrm{C}_{1}$ and $\mathrm{C}_{\mathrm{r}}$ are important in centroid calculation. The centroid can be obtained through equation (6).

Centroid $=\left(\mathrm{C}_{1}+\mathrm{C}_{\mathrm{r}}\right) / 2$

Even though centroid calculation is an iteration process, the number of iteration will not exceeds $\mathrm{N}$, where $\mathrm{N}$ equals the number of sampled values of the primary variable.

\subsection{Interval type-2 fuzzy logic controller}

The model of IT2FLC refers [2] with a type development on fuzzy logic controller block, and to simplify model integrator block is also removed. IT2FLC model is as shown in Fig. 11.

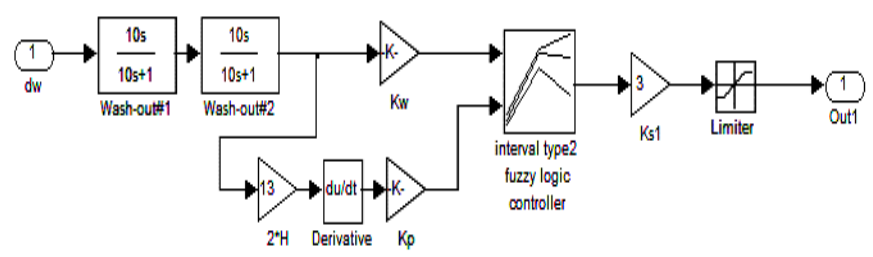

Figure 11. IT2FLC Model

Fig.11 shows that IT2FLPSS consists of blocks, those are wash-out, gain (Kw, Kp, Ks1), and limiter. Each part is explained as follows:

1) Wash Out:This block consists of two wash-out filter with time constant 10 second.

2) Gain [Kw Kp Ks1]: Gain is needed to normalize the input and output of fuzzy logic controller.

3) IT2 Fuzzy Logic Controller:IT2 Fuzzy Logic Controller has a function to produce control signal as an output appropriate with the input. 
4) Limiter [Vsmin Vsmax]: Limiter gives limitation of the IT2FLC output.

In order to set fuzzy logic controller, input membership function, output membership function, rules, and gain tuning are definitive. Detail of input membership function, output membership function, rules, and gain tuning are as follows:

\subsection{Input membership function}

Each of input variables are classified by Input membership function consists of trapezoidal membership function and triangular membership function, described in Fig. 12.

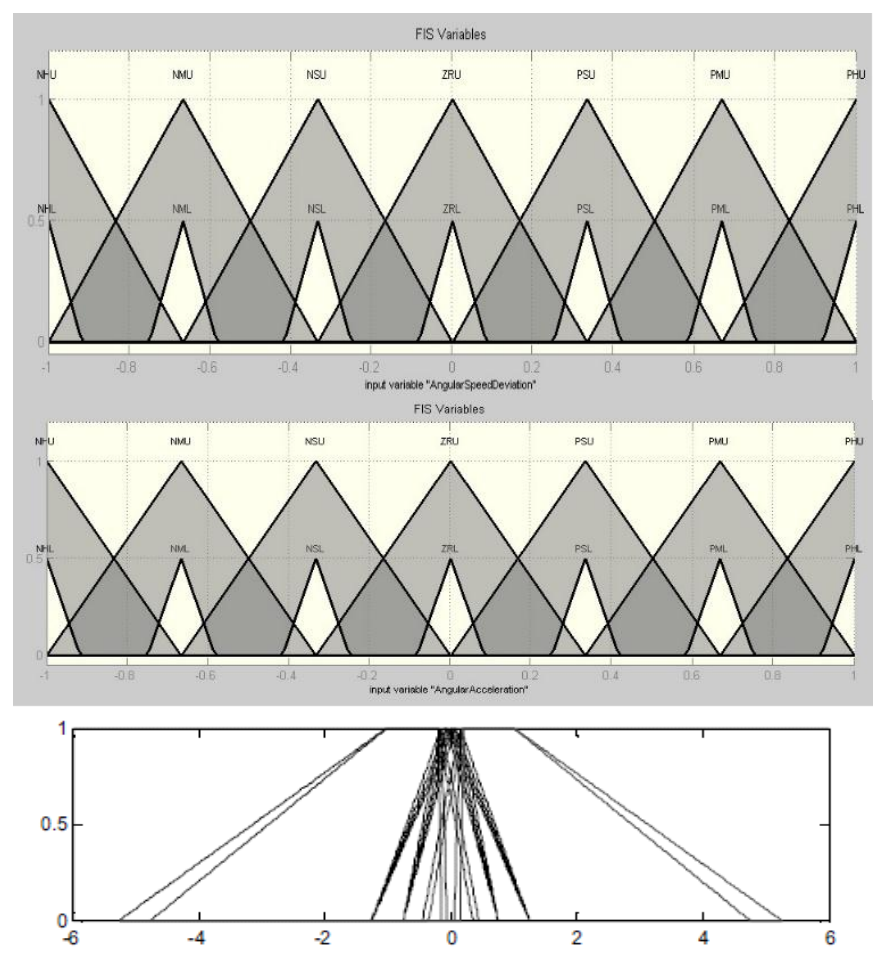

Figure 12. Input membership function

The linguistic variable of input membership shown in Fig. 12 can be described as follows:

\begin{tabular}{|c|c|c|}
\hline $\begin{array}{l}\text { Linguistic } \\
\text { Variables } \\
\end{array}$ & $\begin{array}{c}\text { Upper Membership } \\
\text { Function } \\
\end{array}$ & $\begin{array}{c}\text { Lower Membership } \\
\text { Function } \\
\end{array}$ \\
\hline Big Negative & $\begin{array}{c}\mu \text { i BN_UMF }=[-5-0.25-1- \\
0.20 .1+0.25] ;\end{array}$ & $\begin{array}{c}\mu \text { i BN_LMF }=[-5+0.25-1 \\
-0.20 .1-0.25] ;\end{array}$ \\
\hline $\begin{array}{l}\text { Medium } \\
\text { Negative }\end{array}$ & $\begin{array}{c}\mu \text { i MN_UMF }=[-1-0.25- \\
0.150 .2+0.25]\end{array}$ & $\begin{array}{c}\mu \text { i MN_LMF }=[-1+0.25- \\
0.150 .2-0.25]\end{array}$ \\
\hline Low Negative & $\begin{array}{c}\mu \text { i LN_UMF }=[-1-0.25- \\
0.0651+0.25] ;\end{array}$ & $\begin{array}{c}\mu_{\text {i LN_LMF }}=[-1+0.25- \\
0.0651-0.25]\end{array}$ \\
\hline Zero & $\begin{array}{c}\mu \mathrm{i} \mathrm{Z}_{-} \mathrm{UMF} \\
1+0.25]\end{array}$ & $\begin{array}{c}\mu \text { i } Z_{-} L M F \\
=\left[\begin{array}{lll}-1+0.25 & 0 & 1-\end{array}-\right. \\
0.25]\end{array}$ \\
\hline Low Positive & $\begin{array}{c}\mu_{\mathrm{i} \text { LP_UMF }}=[-1-0.25 \\
0.0651+0.25] ;\end{array}$ & $\begin{array}{c}\mu_{\text {i LP_LMF }}=[-1+0.25 \\
0.0651-0.25]\end{array}$ \\
\hline Medium & $\mu_{\text {i MP_UMF }}=[-0.2-0.25$ & $\mu_{\text {i MP_LMF }}=[-0.2+0.25$ \\
\hline Positive & $0.151+0.25]$ & $0.151-0.25]$ \\
\hline Big Positive & $\begin{array}{c}\mu_{\text {i BP_UMF }}=[-0.1-0.25 \\
0.215+0.25] ;\end{array}$ & $\begin{array}{c}\mu \text { i BP_LMF }=[-0.1+0.25 \\
0.215-0.25] ;\end{array}$ \\
\hline
\end{tabular}

\subsection{Output membership function}

Output membership function also consists of triangular membership function, described in Fig. 13.

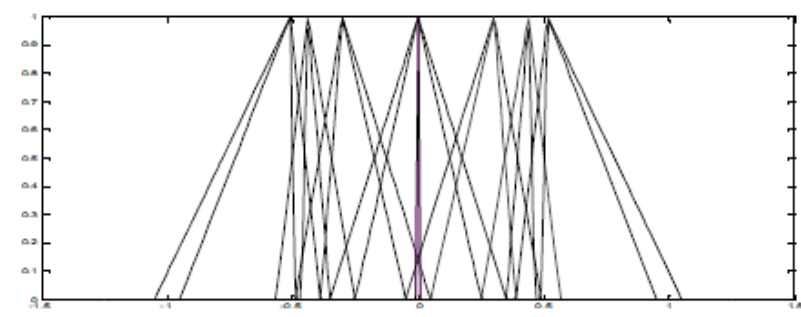

Figure 13. Output membership function

The linguistic variable of output membership shown in Fig. 13 can be described as follows:

\begin{tabular}{|c|c|c|}
\hline $\begin{array}{l}\text { Linguistic } \\
\text { Variables }\end{array}$ & $\begin{array}{l}\text { Upper Membership } \\
\text { Function }\end{array}$ & $\begin{array}{c}\text { Lower Membership } \\
\text { Function }\end{array}$ \\
\hline Big Negative & $\begin{array}{c}\mu_{\mathrm{o} \text { BN_UMF }}=[-1-0.005- \\
0.51-0.439+0.005]\end{array}$ & $\begin{array}{c}\mu \text { o BN_LMF }=[-1+0.005- \\
0.51-0.439-0.005]\end{array}$ \\
\hline Medium & $\mu$ o MN_UMF $=[-0.515-$ & $\mu_{\mathrm{o} \text { MN_LMF }}=[-$ \\
\hline Negative & $\begin{array}{l}0.005-0.439- \\
0.302+0.005]\end{array}$ & $\begin{array}{c}0.515+0.005-0.439- \\
0.302-0.005]\end{array}$ \\
\hline Low & $\mu$ o LN_UMF $=[-0.439-$ & $\mu_{\mathrm{o} \text { LN_LMF }}=[-$ \\
\hline Negative & $0.005-0.3020+0.005]$ & $\begin{array}{c}0.439+0.005-0.3020- \\
0.005]\end{array}$ \\
\hline Zero & $\begin{array}{c}\mu_{\mathrm{o}} \mathrm{Z}_{-} \mathrm{UMF}= \\
0 \\
00.302+0.0005]\end{array}$ & $\begin{array}{c}\mu \circ Z_{-} L_{M F}=[- \\
0.302+0.00500 .302- \\
0.005]\end{array}$ \\
\hline Low Zero & $\begin{array}{c}\mu_{\mathrm{o}} \mathrm{LZ}_{-} \mathrm{UMF}=[-0.0015- \\
0.00050 \\
0.0015+0.0005]\end{array}$ & $\begin{array}{c}\mu_{\mathrm{o} \text { LZ_LMF }}=[- \\
0.0015+0.00050 \\
0.0015-0.0005]\end{array}$ \\
\hline Low Positive & $\begin{array}{l}\mu_{\text {o LP UMF }}=[0-0.005 \\
0.3020 .439+0.005]\end{array}$ & $\begin{array}{c}\mu_{\text {o LP_LMF }}=[0+0.005 \\
0.3020 .439-0.005]\end{array}$ \\
\hline Medium & $\mu_{\mathrm{o}} \mathrm{MP}_{\mathrm{UMMF}}=[0.302-0.005$ & $\mu_{\text {o MP_LMF }}$ \\
\hline Positive & $0.4390 .515+0.005]$ & $\begin{array}{c}=[0.302+0.0050 .439 \\
0.515-0.005]\end{array}$ \\
\hline Big Positive & $\begin{array}{c}\mu \text { o BP_UMF }=[0.439-0.005 \\
0.5151+0.005]\end{array}$ & $\begin{array}{c}\mu \text { o BP_LMF } \\
=[0.439+0.0050 .5151- \\
0.005]\end{array}$ \\
\hline
\end{tabular}

\subsection{Rules}

Rules used by IT2FLC are identical with IT1FLC. The Rules are shown in Table 1.

Table 1. IT2 fuzzy logic rules

\begin{tabular}{|c|c|c|c|c|c|c|c|}
\hline $\begin{array}{c}\text { Angular } \\
\text { Speed } \\
\text { Deviation } \\
\text { Angular } \\
\text { Acceleratio } \\
n\end{array}$ & $\begin{array}{c}\mathrm{NH} \\
\mathrm{U}\end{array}$ & $\begin{array}{c}\mathrm{NM} \\
\mathrm{U}\end{array}$ & $\begin{array}{c}\mathrm{NS} \\
\mathrm{U}\end{array}$ & $\begin{array}{c}\text { ZR } \\
\text { U }\end{array}$ & $\begin{array}{c}\text { PS } \\
\text { U }\end{array}$ & $\begin{array}{c}\mathrm{PM} \\
\mathrm{U}\end{array}$ & $\begin{array}{c}\mathrm{PH} \\
\mathrm{U}\end{array}$ \\
\hline NHU & $\mathrm{NH}$ & $\mathrm{NH}$ & NM & NM & NS & ZR & PS \\
\hline NMU & $\mathrm{NH}$ & NM & NM & NS & ZR & PS & PM \\
\hline NSU & $\mathrm{NH}$ & NM & NS & NS & ZR & PS & PM \\
\hline ZRU & $\mathrm{NH}$ & NM & NS & ZR & PS & PM & $\mathrm{PH}$ \\
\hline PSU & NM & NS & PS & PS & PM & $\mathrm{PH}$ & PM \\
\hline PMU & $\mathrm{NM}$ & NS & ZR & PS & PM & PM & $\mathrm{PH}$ \\
\hline PHU & NS & ZR & PS & PM & PM & $\mathrm{PH}$ & PH \\
\hline
\end{tabular}

\subsection{Gain tuning}

The gains of the proportional and derivative actions of the IT2FLC are given by the following relations:

$\mathrm{K}_{\mathrm{PR}}=\mathrm{Ks} 1 \times\left(\mathrm{F}\left\{\mathrm{K}_{\mathrm{p}}\right\}+\mathrm{F}\{\mathrm{Kw}\}\right), \mathrm{K}_{\mathrm{DER}}=\mathrm{Ks} 1 \times \mathrm{F}\{\mathrm{KP}\}$

With KPR, KDER are proportional gain, derivative gain, and fuzzy operation, respectively. To obtain the gains $\mathrm{Kw}, \mathrm{Kp}$, 
and Ks1 a two steps method has been used. These two steps consist of adjusting $\mathrm{Kp}$ and $\mathrm{Kw}$ in order to normalize input and then tuning Ks1 to obtain best result. The value of $\mathrm{Kw}, \mathrm{Kp}$,

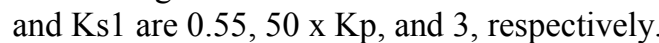

\section{APPLICATION AND SIMULATION RESULTS}

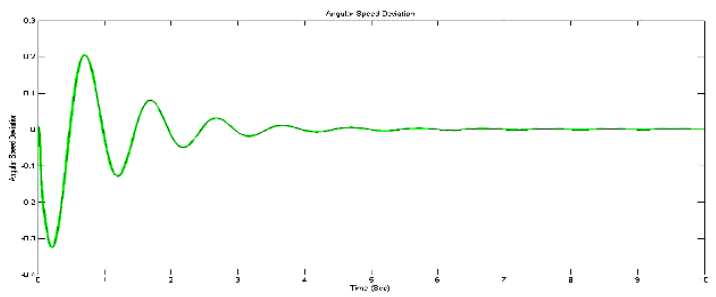

Figure 14. Angular speed deviation

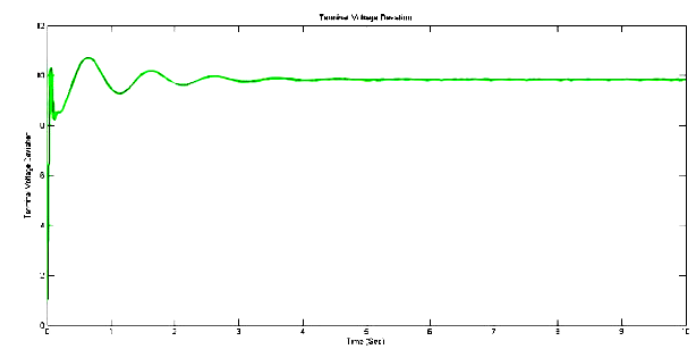

Figure 15. Terminal voltage deviation
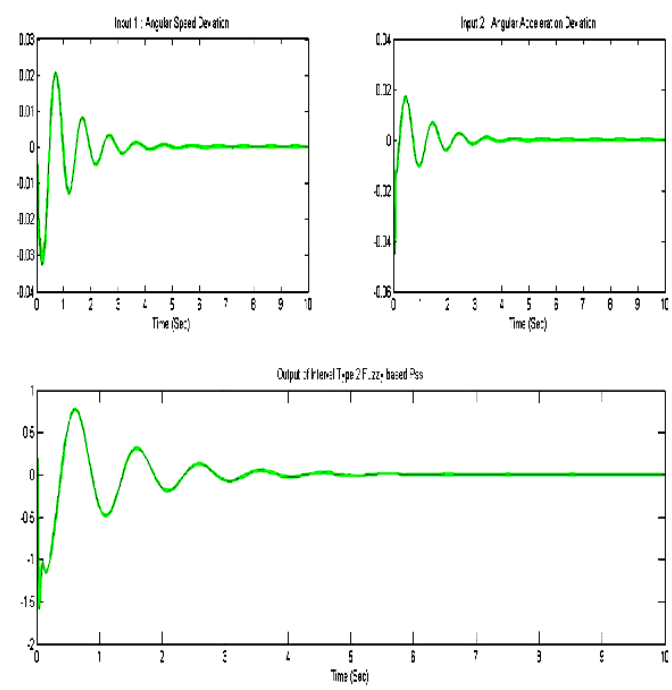

Figure 16. Output of interval type-2 PSS

\begin{tabular}{|c|c|c|}
\hline Model & $\begin{array}{c}\text { Stability Time for } \\
\text { Terminal Voltage } \\
\text { Deviation (In sec) }\end{array}$ & $\begin{array}{c}\text { Stability Time for } \\
\text { Angular Speed } \\
\text { Deviation (In Sec) }\end{array}$ \\
\hline Pss \& AVR & 5.268 & 5.731 \\
\hline $\begin{array}{c}\text { Interval Type 2 } \\
\text { Fuzzy based Pss \& } \\
\text { AVR }\end{array}$ & 4.456 & 5.251 \\
\hline $\begin{array}{c}\text { Interval Type 2 } \\
\text { Fuzzy based Pss \& } \\
\text { Interval Type 2 } \\
\text { Fuzzy based Digital } \\
\text { AVR }\end{array}$ & 3.000 & 3.89 \\
\hline
\end{tabular}

\section{CONCLUSIONS}

Synchronous generator is the source of energy in electrical power system and therefore regulation of synchronous generator affects not only generator itself, but also entire power system. In synchronous generator mechanical energy of rotor is transformed into electrical energy in stator winding. This energy transformation is provided by excitation of synchronous generator and is regulated by excitation system. Excitation system usually consists of autonomic voltage regulator, exciter, measuring elements and power system stabilizer and limitation and protection unit. Excitation system models in the meaning of structure and implemented controller type are classified and standardized. All these models include linear controllers (P, PI or PID controllers) because they are mostly used in practice. Linear regulation is good for stationary state, but in transition state quality of regulation changes with change of operating point, for synchronous generator is a nonlinear system. To solve this problem nonlinear regulation is introduced. Nonlinear regulation may be implemented in form of neural networks, fuzzy control or adaptive control. In this paper excitation control of a power plant alternator using interval type 2 fuzzy logic controller (IT2FLC) is proposed. These structures are more complex than structures of linear regulation, but have potential to improve excitation system regulation with further development.

\section{REFERENCES}

[1] Mao H, Malik OP, Hope GS, Fan J. (1990). An Adaptive Generator Excitation Controller Based on Linear Optimal Control. IEEE Trans. on Energy Conversion 5(4): 673-678. https://doi.org/10.1109/60.63138

[2] Papadopoulos DP. (1986). Excitation Control of Turbogenerators with Output Feedback. Int. J. Electr. Power \& Energy Systems 8: 176-181. https://doi.org/10.1016/0142-0615(86)90032-3

[3] Ross T. (1995). Fuzzy Logic with Engineering Applications. Fuzzy-Logik. https://doi.org/10.1111/j.1468-1331.2005.01230.x

[4] Hassan MAM, Malik OP., Hope GS. (1991). A Fuzzy Logic Based Stabilizer for a Synchronous Machine. IEEE Trans. Energy Conv. 6(3): 407-413. https://doi.org/10.1109/60.84314

[5] Handschin E, Hoffmann W, et al. (1994). A new Method of Excitation Control Based on Fuzzy Set Theory. IEEE Trans. Power Syst. 9: 533-539. https://doi.org/10.1109/59.317569

[6] Djukanovic MB, Dobrijevic DM, Calovic MS, Novicevic M., Sobajic DJ. (1997). Coordinated Stabilizing Control for the Exciter and Governor Loops Using Fuzzy Set Theory and Neural Nets. International Journal of Electrical Power \& Energy Systems 8: 489499. https://doi.org/10.1016/s0142-0615(97)00020-3

[7] Karnavas YL, Papadopoulos DP. (2000). Excitation Control of a Power Generating System Based on Fuzzy Logic and Neural Networks. European Transactions on Electrical Power 10(4): 233-241. https://doi.org/10.1002/etep.4450100406

[8] Karnavas YL, Papadopoulos DP. (2002). A GeneticFuzzy System for the Excitation Control of a Synchronous Machine. ICEM '02, The 15th International Conference in Electrical Machines. 
[9] Hornich K, Stinchcomebe M., White H. (1989). Multilayer Feed forward Networks are Universal Approximators. Neural Networks 2: 359-366. https://doi.org/10.1016/0893-6080(89)90020-8

[10] Karnavas YL, Papadopoulos DP. (2002). AGC for Autonomous Power Station Using Combined Intelligent Techniques. Electric Power Systems Research 62(3): 225-239. https://doi.org/10.1016/s0378-7796(02)000822

[11] Mcclelland J, Rumelhart D. (1987). Parallel Distributed Processing.

[12] Giles CL, Maxwell T. (1987). Learning, Invariance, and Generalization in High-Order Neural Network. Applied Optics 26(23). https://doi.org/10.1364/AO.26.004972

[13] Lippmann RP. (1989). Pattern Classification Using Neural Networks. IEEE Communications Magazine 27(11): 47-64. https://doi.org/10.1109/35.41401

[14] Shin Y, Ghosh J. (1992). Excient Higher-Order Neural Networks for Function Approximation and Classification. Int. J. Neural Syst. 3(4): 323-350.

[15] Robandi I. (2006). Modern Power System Design (Desain System Tenaga Modern, in Bahasa Indonesia), Andi Offset Publisher: 2006.

[16] Dobrescu M, Kamwa I. (2004). A New Fuzzy Logic Power System Stabilizer Performances. IEEE. https://doi.org/10.1109/PSCE.2004.1397498

[17] Kundur P. (1993). Power System Stability and Control. McGraw-Hill.

[18] Ross T, Logik F. (1997). Fuzzy Logic with engineering Applications. McGraw-Hill. https://doi.org/10.1111/j.1468-1331.2005.01230.x

[19] Liangand Q, Mendel JM. (2000). Interval Type-2 Fuzzy Logic System Theory and Design. IEEE. https://doi.org/10.1109/91.873577

[20] Mendel JM, Robert I, John B. (2002). Type-2 Fuzzy Sets Made Simple. IEEE. https://doi.org/10.1109/91.995115

[21] Castro JR, Castillo O. (2007). Interval Type-2 Fuzzy Logic for Intelligent Control Applications. IEEE. https://doi.org/10.1109/NAFIPS.2007.383907

[22] Mendel JM, Liu FL. (2007). Super-Exponential Convergence of the Karnik-Mendel Algorithms for Computing the Centroid of an Interval Type-2 Fuzzy Set. IEEE. https://doi.org/10.1109/tfuzz.2006.882463
[23] Jolevski D. (2009). Excitation System of Synchronous Generator. University of Split, Faculty of Electrical Engineering. Mechanical Engineering and Naval Arhitecture.

[24] Tesnjak S, Erceg G, Erceg R., Klarin D, Komericki Z. (2000). Excitation System of Synchronous Turbo Generator. Thermal Power Plant Features in the Meaning of Electric Power System Demands.

[25] Machowski J, Bialek JW, Robak S, Bumby JR. (1998). Excitation control system for use with synchronous generators. IEE Proc.- Gener. Transm. Distrib. 145(5). https://doi.org/10.1049/ip-gtd:19982182

[26] Sumina D, Erceg G, Idžotic T. (2005). Excitation control of a synchronous generator using fuzzy logic stabilizing controller. https://doi.org/10.1109/EPE.2005.219266

[27] Miskovic M, Mirosevic M, Erceg G. (2009). Load Angle Estimation of a Synchronous Generator Using Dynamical Neural Networks. Energija 58(2): 174-191. https://doi.org/10.1109/MELCON.2004.1348098

[28] Miskovic M, Mirosevic M, Milkovic M. (2009). Analysis of Synchronous Generator Angular Stability depending on the Choise of the Excitation System. Energija 58(4): 430-445.

\section{Appendix A}

Principal system data \& machine operating point (pu values on machine rating)

\begin{tabular}{lll|ll}
\hline Synchronous Machine & $x_{d}$ & $1.758 \mathrm{pu}$ & $R_{a}$ & $0.01450 \mathrm{pu}$ \\
$87.5 \mathrm{kVA}, 415 \mathrm{~V}$, & $x_{q}$ & $0.990 \mathrm{pu}$ & $R_{k d}$ & $0.00422 \mathrm{pu}$ \\
4-pole & $x_{f d}$ & $1.761 \mathrm{pu}$ & $R_{k q}$ & $0.01260 \mathrm{pu}$ \\
& $x_{k d}$ & $1.664 \mathrm{pu}$ & $R_{f d}$ & $0.00268 \mathrm{pu}$ \\
& $x_{k q}$ & $0.955 \mathrm{pu}$ & $H$ & $1.434 \mathrm{~s}$ \\
& $x_{m d}$ & $1.658 \mathrm{pu}$ & & \\
& $x_{m q}$ & $0.899 \mathrm{pu}$ & & \\
\hline Conventional Exciter & $K_{e}$ & 1 & $T_{e}$ & $0.472 \mathrm{~s}$ \\
\hline Transformer & $R_{T}$ & $0.03630 \mathrm{pu}$ & $X_{T}$ & $0.0838 \mathrm{pu}$ \\
\hline Transmission line & $R_{L}$ & $0.03744 \mathrm{pu}$ & $X_{L}$ & $0.3903 \mathrm{pu}$ \\
\hline$P_{t} Q_{t}$ & $u_{t}$ & $u_{f d}$ & $\delta$ & $U_{b}$ \\
\hline $0.8 \mathrm{pu} \quad 0.84 \mathrm{pu}$ & $1.29 \mathrm{pu}$ & $0.0043 \mathrm{pu}$ & $0.56 \mathrm{rad}$ & $0.97 \mathrm{pu}$
\end{tabular}

